\title{
A panel data analysis of the effects of wages, standard hours and unionisation on paid overtime work in Britain
}

\author{
Adriaan S. Kalwij* \\ Department of Economics, Tilburg University, Tilburg, The Netherlands \\ Mary Gregory \\ Department of Economics, University of Oxford, Oxford, United Kingdom
}

Revised 8 October 2003, Revised: 23 February 2004, Final Version 27 April 2004

* Address for correspondence: Room B933, Department of Economics, Tilburg University, PO Box 90153, 5000 LE Tilburg, The Netherlands. (Email: kalwij@uvt.nl) 


\section{A panel data analysis of the effects of wages, standard hours and unionisation on paid overtime work in Britain}

\section{Summary}

This study examines the effects of the basic wage rate, standard working hours and unionisation on paid overtime work in Britain using individuallevel data from the New Earnings Survey over the period 19752001. For this purpose we estimate a panel data model. We show that to obtain consistent estimates it is important to allow for both the censoring of paid overtime hours at zero and for correlations between the explanatory variables and unobserved individual specific effects. The main empirical results are that a reduction in standard hours increases both overtime incidence and overtime hours, while an increase in the wage rate decreases the incidence of overtime but brings a small increase in overtime hours for those working overtime. For men the effects are stronger than for women. Union coverage is of minor empirical importance. The occupation and industry structure of employment has shifted from high to lower overtime jobs. Taken together, these economic variables can explain almost half of the changing incidence of overtime for men, and most of the change in overtime hours worked by women, but are less successful in explaining the changes in overtime hours worked by men or the incidence of overtime for women.

Keywords: Panel data, Censoring, Overtime work

JEL-codes: C23, C24, J2 


\section{Introduction}

An important determinant of the level of employment is the division of any increase in demand for labour services between an increase in hours worked and an expansion of employment. While the evolution of employment has received intensive scrutiny in both analysis and policy-making, much less attention has been given to the intensive margin of labour adjustment, i.e. the use of overtime hours. Currently in Britain paid overtime is worked by one-third of male employees, 7-9 hours per week on average, and by almost one-fifth of female employees, 3-4 hours per week on average (see Table 1 below). These figures are in line with other observations for Britain by Bell and Hart (1998), and for the US (Trejo, 1993) and Germany (Bauer and Zimmermann, 1999). This shows that paid overtime makes up a significant proportion of hours worked, and consequently of the labour costs of firms and the labour income of households.

The economic analysis of overtime hours has been extensively developed over a number of years (see Hamermesh, 1993, Pencavel, 1986, Hart, 1987). A seminal article on the division of labour demand over employment and hours is Calmfors and Hoel (1988). In their model the firm chooses the number of workers and hours per worker to minimise labour costs, given the labour requirements for a fixed level of output, a fixed cost of employing each worker, the wage rate, standard hours and the overtime premium. This model yields the following well-known predictions: the demand for hours per worker is decreasing in standard hours, the wage rate and the overtime premium, and increasing in the fixed cost of labour. The negative relationship between standard hours and the demand for hours per worker, which may seem counterintuitive, derives from the fact that, when overtime is being worked, a reduction in standard hours increases the average labour cost per hour while the marginal cost remains constant. In the model of Calmfors and Hoel overtime hours are set by labour demand, but clearly actual overtime hours also involve supply considerations. The supply of overtime hours will respond to changes in the wage rate, depending on the preferences of individuals over income and leisure via the familiar income and substitution effects. 
While a higher wage induces substitution of work for leisure, a dominating income effect will reduce the hours supplied in favour of leisure (e.g. Nickell, 1983). An alternative to the labour demand or 'fixedwage' approach above views hours worked as the outcome of a joint earnings-hours contract between firms and workers which reflects the preferences of both sides. Trejo $(1991,2003)$ postulates a compensating differential or 'fixed-job' model in which workers and firms agree on a package of weekly earnings and weekly hours. Within this fixed package, a change in standard hours or the overtime premium can be absorbed by an offsetting change in the (possibly implicit) straight-time hourly wage rate. As in the fixed-wage model, a reduction in standard hours yields an increase in overtime hours. In further extensions, the presence of unions becomes an additional influence on overtime hours through bargaining over the conditions for overtime work (see, e.g., Contensou and Vranceanu, 2000).

Several recent studies report microeconometric evidence on the determinants of overtime work, mostly at the individual level (Trejo, 1993; Bell and Hart, 1998; Hunt, 1999; Bauer and Zimmermann, 1999). Hunt examines the effects of a reduction in standard hours on paid overtime for Germany. Using data from the German Socio-Economic Panel, she concludes that, at least for hourly paid workers in manufacturing, a one-hour reduction in standard working hours leads to a fall in actual hours of between 0.88 and 1.0, suggesting a small increase in overtime hours, of up to 0.12 hours. Bauer and Zimmermann, on the other hand, again for Germany, find that lower standard hours reduce overtime; this is in contrast to the predictions from the theoretical models. Bell and Hart, find that, for the UK, a rise in the basic hourly wage is associated with a fall in total weekly hours worked, consistent with the labour demand approach above. Trejo, on the other hand, indicates for the US that overtime hours increase with the wage rate, consistent with the substitution effect dominating in labour supply. On the role of union bargaining, Bell and Hart find no significant effect for the UK. For the US, on the other hand, Trejo concludes that the presence of unions increases the prevalence of premium pay for overtime, and reduces the incidence and hours of overtime. 
The comparison of the results above is conditioned by the differing methodologies adopted in the various studies. Trejo (1993) uses a Tobit model estimated on a single cross section. The use of a Tobit model takes into account the censoring of overtime hours at zero (Tobin, 1958). However, a well-known limitation of the use of cross-section data is that one cannot control for correlations between the explanatory variables and unobserved individual specific effects such as preferences over income and leisure. If these unobserved characteristics are correlated with the explanatory variables, parameter estimates are potentially biased. When available, panel data provide a route to overcoming this problem. Both Hunt (1999) and Bell and Hart (1998) exploit panel data to estimate a linear fixed effects model. While allowing for correlations between the explanatory variables and unobserved individual specific effects, the fixed effects estimator employed in these panel studies does not take into account the censoring of overtime hours at zero, and hence may yield inconsistent parameter estimates. Bauer and Zimmermann (1999) have panel data and take into account the censoring of overtime hours at zero but do not allow for correlations between the explanatory variables and unobserved individual specific effects. In this respect their approach is similar to the cross-sectional approach of Trejo (1993) discussed above.

The contribution of this paper is two-fold. On the methodological side to analyse paid overtime hours we use a panel data model that takes into account the censoring of overtime hours at zero for those not working paid overtime while also controlling for correlations between unobserved individual specific effects and the explanatory variables in a pre-specified way. This panel data model is based on Wooldridge (1995), Rochina-Barrachina (1999) and Kalwij (2003). To analyse the incidence of paid overtime we follow Hunt (1999). On the empirical side we extend the previous studies by analysing the effects on the incidence and hours of paid overtime of all three economic determinants identified above: changes in standard hours, the real wage rate, and unionisation. Furthermore, we examine the extent to which the estimates of the parameters of interest are biased when more restrictive econometric models are used, as in Trejo (1993), Bell and Hart (1998), Hunt (1999) and Bauer and Zimmermann (1999). 
Our focus is the British economy. This provides a particularly interesting test-bed for the analysis of paid overtime work due to the absence of legal regulation of hours of work and overtime conditions. There is, for example, no parallel to the Standard Labor Act in the US, which mandates an overtime premium of $50 \%$ for hours worked beyond 40 per week. The recently introduced EU Working Time Directive may, at most, affect the last two years of our sample period. Traditionally unions have played an important role in negotiating the conditions for overtime working, such as the wage premium, as well as standard hours and wage rates. However, beginning with the Thatcher reforms, the last 20 years have seen deep-seated changes in relations between employers and employees, leading to the suggestion that the decline of union membership and collective agreements may have altered the use of overtime, potentially in the direction of employer preferences (Beatson, 1995).

For the estimation we exploit the New Earnings Survey Panel Dataset (NESPD). The NESPD provides a long and very large panel, covering about 165,000 employees per year over the period 19752001. This is the same dataset as used by Bell and Hart (1998, 1999a). In line with the studies discussed above, we analyse only paid overtime hours, as our dataset gives no information on unpaid overtime. An analysis of unpaid overtime is provided in Bell and Hart (1999).

The remainder of the paper is structured as follows. Section 2 describes the NESPD data and the construction of the sample, and gives some leading descriptive statistics. Section 3 presents the econometric framework. Section 4 reports the estimation results and comparisons with previous studies. Section 5 concludes.

\section{The New Earnings Survey 1975-2001}


The New Earnings Survey (NES) is an annual cross-section survey of earnings and hours of work at the individual level of employees in employment in Great Britain. The information is supplied by employers from payroll records and the data are gathered by the Office of National Statistics (ONS). All employees who have a National Insurance (NI) number that ends with a specified pair of digits form the sample. Since an NI number is issued to each individual at the minimum school-leaving age, the sampling frame for the Survey is a $1 \%$ random sample of the potential employed population. The same pair of terminating digits from the NI number is used as the basis for each year's sample, generating an unbalanced panel from the annual cross-section Surveys. The panel is characterised by new individuals entering the sample when starting employment and individuals exiting on retirement; in addition, unemployment and temporary withdrawal from the labour force generate gaps in individual participation. This unbalanced panel is referred to as the NESPD. In this study the panel covers the period 1975-2001.

The NESPD contains detailed information on the individual's gross weekly basic pay and overtime pay, standard working hours and paid overtime hours. Further information includes the employee's age, gender, job-tenure, union coverage and occupation, along with the employing establishment's industrial classification and regional location. As is most often the case with administrative data, the NESPD contains only limited information on individual characteristics and none at all on the household. In particular, human capital measures such as educational attainment, and household characteristics such as marital status and presence of children, are not available in the data.

\subsection{Definitions and data selection}

The dependent variable we use in the empirical analysis is weekly paid overtime hours, referred to as overtime hours. The Survey asks two questions on the individual's hours of work: 'Basic weekly hours of work. During the pay period, what was the average number of hours paid at basic rate of pay? (include all guaranteed hours, even if not worked)'; this is used as the measure of standard hours. 
And: 'Overtime hours during the pay period. How many overtime hours were worked during the pay period? (the hours must be consistent with the overtime earnings reported)'. The Survey does not distinguish different types of overtime hours, such as extra hours on the normal workweek, or additional weekend working. The overtime premium is not recorded, and no questions are asked on unpaid overtime. Where the reported pay period is not a week, data are converted by ONS to a weekly basis, located at the specified Survey week in April of each year.

The basic wage rate is calculated as basic pay divided by standard hours, where basic pay is defined in the Survey as gross weekly earnings, less overtime pay, bonus and incentive payments and any premium paid for shift-working. We convert all wage rates to $2001 £$ s, with deflation by the retail prices index. Responses to the question 'Has the employee worked at this job in your organisation for one year or more?' allow us to determine whether the individual is a recent job-changer. Union coverage is based on whether the individual's pay and working conditions are set by a major industry or national collective agreement. We also use 1990 Standard Occupational Classification (SOC) at the level of 9 Major Groups and 1995 Standard Industrial Classification (SIC) at the 1-digit level (13 groups). The region in which the worker's establishment is located is distinguished at the level of the 11 Standard Regions. These fairly aggregated classifications are used to provide consistency across the observation period during which the classification systems were changed on several occasions.

Table A1 in Appendix A provides a detailed overview of the data selection process. The raw unbalanced panel for 1975 to 2001 contains almost four and a half million observations on about half a million individuals. The reasons for dropping observations are presented incrementally, starting from hours of work as our central variable of interest. However, in many cases the same record is characterised by several items of deficient data, notably pay and hours jointly, so that the reason for discard may depend somewhat arbitrarily on sequence in the screening. Missing information on standard working hours or overtime hours leads to the exclusion of $16 \%$ of observations. Until 1994 an employee could be reported 
as working full-time but without specified hours. This was discontinued from 1995, leading to a fall in the number with missing hours from that date. Increasingly stringent requirements on contracts of employment over recent years have also led to more systematic specification of contractual hours of work. The fall in missing hours from 1998 is due to a change in the coding applied by ONS. Previously when pay was affected by absence hours were coded as missing; from 1998 they are set to standard hours, with these observations then removed due to missing pay information. Missing hours data prevent the calculation of the employee's hourly wage, leading to missing pay information as we require it. Records are also excluded on the grounds of missing pay information when earnings are not reported, pay is affected by absence, or the employee is a multiple jobholder with more than one employer. A small number of further cases are excluded because of missing values for the industry, occupation or regional codes (1.7\%). All observations attributed to an individual are excluded if sex changes over the observation period (2\%) or age does not increase by one year, plus or minus one, per calendar year (age inconsistencies, $0.3 \%$ ). In total, exclusions due to these data deficiencies cause a $22 \%$ reduction of the sample. In addition the Survey will capture individuals employed while in education or in retirement. To avoid results being influenced by this we exclude those aged under 21 or over 59 (a further $10 \%$ reduction). To ensure robustness of the empirical results against outliers or extreme errors of measurement we exclude individuals with wage rates or hours in the top or bottom percentile of the respective distribution. This excludes on average $2.5 \%$ of the observations per year. Finally, the empirical analysis exploits the fact we have panel data and uses only those individuals who are observed in two consecutive periods. This causes an $8.4 \%$ reduction in the sample, with this selection of course largest in the end-years 1975 and 2001 . The final sample used in the empirical analysis comprises 2,547,003 observations on 300,171 individuals with on average around 94,000 individuals present in any year.

\subsection{Panel attrition}


The NES is designed as a series of representative cross section surveys, and it is the incidental feature that the same terminating digits on the NI number are used to draw the sample each year that makes it possible to construct the panel. Consequently, at the stage of data gathering little attention is paid to the panel aspect, and possible selection problems that may arise in the NESPD from sample attrition.

As mentioned above, the NES is framed as a $1 \%$ sample of the employed population. Table A2 in Appendix A shows that the actual percentage of the employed population covered by the NESPD in any year varies between 0.52 and $0.73 \%$. Our final sample, after exclusions, is about one-third of one per cent of the employed population. Under-representation is to be expected given definitional differences, notably the exclusion from the NES of the self-employed (2.3 million individuals in 1975 rising to 3.3 million in 2001). Nevertheless, the non-response in the NESPD may be higher than one would expect in administrative data. As a check that coverage of female employment is not differentially restricted a comparison of the female share in employment between the OECD, based on the Labour Force Survey, and the NESPD shows that they are very close especially in the later years (Table A2, Appendix A). A comparison of working hours shows that the NESPD systematically under-samples low-hours jobs (last two columns, Table A2). We return to this issue below.

Table A3, Appendix A, examines non-response from a further angle. The Table reports the percentage of individuals who are observed in the sample in both years $t$ and $t-s$. In the final sample, $80 \%$ of men and $78 \%$ of women observed in year $t$ were also present in year $t-1$, with $59 \%$ of men and $55 \%$ of women also observed in $t$-2. This percentage decreases towards $0 \%$ for years $t$ and $t$-26. The percentages for women are marginally lower than for men. In principle, if all individuals were in continuous employment from age 21 to age 59 then we should observe $100 \%$ for each value of $s$ for the birth-cohorts 1942-1954. Table A3 shows that this is far from the case, and that for these cohorts the patterns are fairly similar to those of the sample of all birth-cohorts. We have to accept that non-negligible panel attrition is present in the NESPD despite the administrative nature of the data. 
Absence from the NESPD while in employment can occur for two main reasons. The first relates to the way the data are gathered. Around $10 \%$ of the sample derives from responses provided directly to ONS by large public and private organizations from their computerised administrative databases. For the remaining 90\%, employees with the appropriate NI numbers are located through the Inland Revenue register of current Pay-As-You-Earn (PAYE) income tax records, and a Survey questionnaire then sent to the employer for (compulsory) completion. The employer is not required to include in the tax register employees whose earnings fall below the tax threshold, potentially excluding many low-wage, short-hours workers. In 1999-2001, for instance, the threshold represented around 22 hours of work per week at the national minimum wage. However, in spite of the relatively high incidence of part-time work and low pay among women Table A2 does not support the inference that the procedure for sample location leads to the under-representation of women in the NESPD. Along with the presence of substantial numbers of lowwage, low-hours workers in the Survey this suggests that many employers find it convenient not to screen out those below the tax threshold from their tax returns, reducing attrition from this source. The second main reason for absence is the time lapse between the inspection of the tax register and the Survey week. This period between sampling and actual data gathering tends to be around one month. During this time a proportion of employees will have changed jobs and consequently no longer be on the payroll at the contacted employer. Thus employees with high rates of job turnover are likely to be under-represented in the sample. This kind of attrition would be endogenous in our study if a high rate of job turnover is associated with overtime hours. We examined this issue more formally by analysing the effects of overtime incidence and hours on the probability of being in the sample in the following year. The results of this analysis, available upon request from the authors, show that for almost all years there is no significant effect of overtime work on the probability of presence in the sample in the following year; the small number of significant cases includes both positive and negative effects. This suggests that endogenous selection is not a major issue for this study. Further, it can be argued that the unbalanced panel used here 
may suffer far less from endogenous selection than some of the data used in previous studies. The location of each year's sample independently through the current tax register means that an employee who was not in work or was missed for any Survey should be located in any future employment. Attrition should not be cumulative. Having said this, we note that we do not have the information to control for endogenous selection if it were present. That sample attrition is exogenous is therefore a recessary assumption throughout the paper.

The advantages of the NESPD should also be emphasised. The consistency of the questionnaire over time and the ability to follow such a large sample of employees, on average 165.000 per year, for up to 27 years, is unique for micro-data. The questionnaire is sent to the employer who is under a legal obligation to complete it (Statistics of Trade Act 1947), ensuring a response rate significantly higher than in household based surveys. The data is provided from payroll records, giving a very high degree of accuracy in the hours and earnings information. Kalwij and Alessie (2003) report that the variance in earnings in the British Household Panel Study is four times that of the variance of earnings in the NESPD, suggesting a much lower measurement error in administrative data.

\subsection{Descriptive statistics}

Table 1 reports the basic descriptive statistics for selected years, separately for men (Panel A) and women (Panel B). Over the sample period the British labour market underwent significant changes. The most notable features observable from the Table are the increase in the female share in total employment, now approaching half of the workforce, and a substantial decline in union coverage for both men and women. The average age of the workforce has remained fairly constant. The percentage of workers with job tenure of less than one year is highly cyclical, and rather higher for women than for men, consistent with their lower labour force attachment. For both men and women the average real (basic) wage rate increased by over $50 \%$ while wage inequality widened, particularly in the upper half of the distribution. 
Median standard hours of work declined slightly for both men and women. Defining part-time work as less than 30 standard hours per week, the incidence of part-time work increased among both men and women. Appendix B reports the distribution of employment over occupations and industries. In general employment has shifted from blue to white-collar occupations and from manufacturing, utilities and construction to service industries, notably financial and business services, and education.

Panel A shows that the incidence of paid overtime work for men remained fairly constant until 1990 and declined thereafter. For women the pattern is reversed (Panel B): a sharp increase in the incidence of overtime until 1990, followed by only a marginal decrease. The average number of paid overtime hours worked by those working overtime fluctuates within relatively narrow bands, between 7.1 and 8.7 hours per week for men and between 3.4 and 3.9 hours for women. For men overtime hours can be observed to decrease in the second half of the 1990s. Appendix B shows that overtime incidence and overtime hours vary substantially across occupations and industries. For men high overtime jobs are in craft, semi-skilled and unskilled manual occupations, and in the transport, agriculture and engineering industries. For women they are in sales and machine operator jobs and again in transport industries. Overall Table 1 shows that in Britain paid overtime hours are a major and persistent feature of employment and not simply, or even primarily, a device for firms to accommodate cyclical variation in labour demand. This is in line with earlier observations for the UK during the 1950s and 1960s (Sallis, 1970) and for the US (Lilien and Hall, 1986).

\section{Econometric framework}

This Section outlines the econometric framework for analysing the determinants of the incidence of paid overtime and of paid overtime hours for those working overtime. A central feature is allowing for 
correlations between the explanatory variables and the unobserved individual specific effects. The proposed framework is a reduced form approach, as in the studies discussed in the introduction. Ideally one would like to estimate a complete (structural) model explaining the changes in the incidence and hours of overtime simultaneously. There is, however, no standard econometric framework for estimating a panel data censored regression model in which one allows for (unrestricted) correlations between the observable characteristics and the unobserved individual specific effects. For an excellent survey of the estimation of nonlinear models with panel data we refer to Honoré (2002).

Section 3.1 follows Hunt (1999) and specifies a linear probability model of the determinants of the incidence of overtime. This model is estimated in first-differences to allow for possible correlations between the observable characteristics and the unobserved individual specific effects. Section 3.2 specifies a relatively new estimator for analysing overtime hours for those who work overtime, based on Rochina-Barrachina (1999) and Kalwij (2003). These authors propose an estimation strategy for a censored regression model that eliminates the individual specific effects from the main equation by taking first-differences. Both studies show that taking first-differences significantly reduces the sensitivity of the estimates to a specific parameterization of the individual specific effects based on the so-called conditional mean independence assumption (Wooldridge, 1995). The proposed model in this study is estimated using a two-step estimator in the spirit of Heckman (1976). This model nests the model estimated by Hunt (1999) for analysing overtime hours conditional on working overtime.

Throughout this section the basic notation is as follows: the index for the individual is $i$, the number of individuals is equal to $N$, and the index for calendar year $t$. Overtime incidence is denoted by $I_{i t}$ (a dummy variable), overtime hours is denoted by $V_{i t}$, and the explanatory variables are denoted by $X_{i t}$.

\subsection{Overtime incidence}


We follow Hunt (1999) and specify a linear probability model to analyse the incidence of paid overtime. The incidence of paid overtime $I_{i t}$ is assumed to relate to the explanatory variables $X_{i t}$ as follows:

$$
I_{i t}=X_{i t} \delta+\zeta_{i}+\eta_{i t}
$$

The error term $\eta_{i t}$ is an idiosyncratic term with mean zero and assumed independent of the explanatory variables. The unobserved individual specific effect is denoted by $\zeta_{i}$ and is allowed to correlate with the explanatory variables. The advantage of using a linear probability model over, for instance, a probit model, is that the unobserved individual effect can be differenced out:

$$
\Delta I_{i t}=\Delta X_{i t} \delta+\Delta \eta_{i t}
$$

where $\Delta I_{i t}=I_{i t}-I_{i t-1}, \Delta X_{i t}=X_{i t}-X_{i t-1}$ and $\Delta \eta_{i t}=\eta_{i t}-\eta_{i t-1}$. Equation (2) is estimated using a Least Squares estimator and the standard errors are adjusted for heteroscedasticity and clustering, since we have multiple observations per individual. An empirical consequence of employing a first-difference estimator is that age and year effects are no longer separately identified (Heckman and Robb, 1985). Therefore we cannot report on the parameter estimates of age and we omit the estimates of the timedummy variables from the results Tables since they include age effects.

\subsection{Overtime hours}

We employ a relatively new econometric method for analysing paid overtime hours. This estimator is based on Tobin (1958), Wooldridge (1995), Rochina-Barrachina (1999) and Kalwij (2003). Paid overtime hours $V_{i t}$ is assumed to relate to the explanatory variables $X_{i t}$ as follows:

$$
\begin{aligned}
& V_{i t}^{*}=X_{i t} \beta+\alpha_{i}+\varepsilon_{i t}, \\
& V_{i t}=\max \left(0, V_{i t}^{*}\right),
\end{aligned}
$$


where $V_{i t}^{*}$ is the latent dependent variable and $V_{i t}$ is the observed overtime hours and is censored at zero. The unobserved individual specific effect is denoted by $\alpha_{i}$ and is allowed to correlate with the explanatory variables. The error term $\varepsilon_{i t}$ is assumed to be a normal random variable with mean zero and variance $\sigma_{t}^{2}, \varepsilon_{i t} \sim N\left(0, \sigma_{t}^{2}\right)$, and is allowed to be serially correlated.

Following Kalwij (2003) the first step is to eliminate the individual specific effects from the main equation, equation (3), by taking first differences:

$$
\begin{aligned}
& \Delta V_{i t}^{*}=\Delta X_{i t} \beta+\Delta \varepsilon_{i t} \\
& \Delta V_{i t}=\left\{\begin{array}{ccccc}
\Delta V_{i t}^{*} & \text { if } & V_{i t-1}^{*}>0 & \text { and } & V_{i t}^{*}>0 \\
0 & \text { if } & V_{i t-1}^{*} \leq 0 & \text { and } & V_{i t}^{*} \leq 0 \\
V_{i t}^{*} & \text { if } & V_{i t-1}^{*} \leq 0 & \text { and } & V_{i t}^{*}>0 \\
-V_{i t-1}^{*} & \text { if } & V_{i t-1}^{*}>0 & \text { and } & V_{i t}^{*} \leq 0
\end{array}\right.
\end{aligned}
$$

where $\Delta V_{i t}^{*}=V_{i t}^{*}-V_{i t-1}^{*}, \Delta V_{i t}=V_{i t}-V_{i t-1}$ and $\Delta \varepsilon_{i t}=\varepsilon_{i t}-\varepsilon_{i t-1}$. Although the individual specific effects are eliminated from Equation (5), estimating it by Least Squares on a sub-sample of individuals with positive hours of overtime in periods $t$ and $t-1$ yields inconsistent estimates because, generally, $E\left[\Delta \varepsilon_{i t} \mid V_{i t-1}^{*}>0, V_{i t}^{*}>0\right] \neq 0$. Therefore a correction for censoring has to be applied that is somewhat more complicated than in the cross-sectional case (Tobin, 1958). A further complication is that, as implied by equation (6), the individual specific effects will still appear in the correction term for the censoring of overtime hours at zero (Kalwij, 2003).

To deal with possible correlations between the unobserved individual specific effects and the explanatory variables we make the so-called conditional mean independence assumption (Wooldridge, 1995). The conditional mean independence assumption made in this study is:

$$
\alpha_{i}=\bar{X}_{i} \gamma+\mu_{i}
$$


where $\bar{X}_{i}$ is the average over time of the explanatory variables and the random individual specific effect $\mu_{i}$ is assumed to be a normal random variable with mean zero and variance $\sigma_{\mu}^{2}, \mu_{i} \sim N\left(0, \sigma_{\mu}^{2}\right)$. This specification is a popular one because in the case of a linear regression model this would yield the familiar fixed effects estimates (Mundlak, 1978). The conditional mean independence assumption is implemented empirically by substituting equation (7) in equation (3):

$$
\begin{aligned}
& V_{i t}^{*}=X_{i t} \beta+\bar{X}_{i} \gamma+u_{i t}, \\
& V_{i t}=\max \left(0, V_{i t}^{*}\right),
\end{aligned}
$$

with $u_{i t}=\mu_{i}+\varepsilon_{i t}$ and $\sigma_{u, t}^{2}=\sigma_{\mu}^{2}+\sigma_{t}^{2}$. The correlation between $u_{i t-1}$ and $u_{i t}$ is denoted by $\rho_{t}$. Kalwij (2003) derives a Maximum Likelihood estimator for a model as specified by equations (8) and (9) based on taking first differences of the equation of interest, as in equations (5) and (6), thereby eliminating the individual specific effect from the main equation. He further shows that taking first-differences helps to alleviate the sensitivity of the estimates to a specific parameterization of the individual specific effects (equation (7)). A more convenient way of estimating this proposed first-difference panel data Tobit model is to use a two-step estimator, in the spirit of Heckman (1976). A two-step estimator for a panel data selection model based on taking first differences of the equation of interest is developed by RochinaBarrachina (1999). Kalwij (2003a) presents a formal derivation and shows that a two-step first-difference estimator for a panel data Tobit model is a special case of her estimator. We develop this as the econometric framework for analysing overtime hours.

The expectation of the first-difference of equation (8) conditional on the individual being observed to work overtime in two consecutive years is given by (see Kalwij, 2003a):

$$
E\left[\Delta V_{i t} \mid V_{i t-1}^{*}>0, V_{i t}^{*}>0\right]=\Delta X_{i t} \beta+\pi_{t} \Lambda_{t}\left(M_{i t-1}, M_{i t}, \rho_{t}\right)-\pi_{t-1} \Lambda_{t-1}\left(M_{i t-1}, M_{i t}, \rho_{t}\right)
$$

with

$$
\pi_{t-1}=\left(\sigma_{t-1}-\rho_{t} \sigma_{t}\right)
$$




$$
\begin{aligned}
& \pi_{t}=\left(\sigma_{t}-\rho_{t} \sigma_{t-1}\right), \\
& M_{i t-1}=\left(X_{i t-1} \beta+\bar{X}_{i} \gamma\right) / \sigma_{u, t-1}, \\
& M_{i t}=\left(X_{i t} \beta+\bar{X}_{i} \gamma\right) / \sigma_{u, t}, \\
& \Lambda_{t-1}\left(M_{i t-1}, M_{i t}, \rho_{t}\right)=\frac{\phi\left(M_{i t-1}\right) \Phi\left(\left(M_{i t}-\rho_{t} M_{i t-1}\right) / \sqrt{1-\rho_{t}^{2}}\right)}{\Phi^{2}\left(M_{i t-1}, M_{i t}, \rho_{t}\right)} \\
& \text { and } \quad \Lambda_{t}\left(M_{i t-1}, M_{i t}, \rho_{t}\right)=\frac{\phi\left(M_{i t}\right) \Phi\left(\left(M_{i t-1}-\rho_{t} M_{i t}\right) / \sqrt{1-\rho_{t}^{2}}\right)}{\Phi^{2}\left(M_{i t-1}, M_{i t}, \rho_{t}\right)} .
\end{aligned}
$$

The standard normal distribution function is denoted by $\Phi($.$) , the standard normal density function by \phi($. and the bivariate standard normal distribution function is denoted by $\Phi^{2}($.$) . The two correction terms on$ the RHS of equation (10) are now added and subtracted from the first-difference of equation (8):

$$
\Delta V_{i t}=\Delta X_{i t} \beta+\pi_{t} \Lambda_{t}\left(M_{i t-1}, M_{i t}, \rho_{t}\right)-\pi_{t-1} \Lambda_{t-1}\left(M_{i t-1}, M_{i t}, \rho_{t}\right)+\xi_{i t}
$$

where $\xi_{i t}$ is an error term with a conditional expectation equal to zero, i.e. conditional on the individual being observed to work overtime in two consecutive years.

Following Kalwij (2003a), equation (11) is estimated in two steps. In the first step the following bivariate probit model is estimated:

$$
\begin{array}{ll}
V_{i t-1}^{*}=X_{i t-1} \beta+\bar{X}_{i} \gamma+u_{i t-1} & V_{i t}^{*}=X_{i t} \beta+\bar{X}_{i} \gamma+u_{i t}, \\
I_{i t-1}=\left\{\begin{array}{lll}
0 & \text { if } & V_{i t-1}^{*} \leq 0 \\
1 & \text { if } & V_{i t-1}^{*}>0
\end{array},\right. & I_{i t}=\left\{\begin{array}{lll}
0 & \text { if } & V_{i t}^{*} \leq 0 \\
1 & \text { if } & V_{i t}^{*}>0
\end{array}\right.
\end{array}
$$

The dependent variables are the indicators for working overtime in the two periods, i.e. $I_{i t-1}$ and $I_{i t}$.

Using Maximum Likelihood to estimate this bivariate probit model yields estimates for $\beta_{t-1}=\frac{\beta}{\sigma_{u, t-1}}$, $\beta_{t}=\frac{\beta}{\sigma_{u, t}}, \gamma_{t-1}=\frac{\gamma}{\sigma_{u, t-1}}, \gamma_{t}=\frac{\gamma}{\sigma_{u, t}}$, and $\rho_{t}$. These first step estimates are obtained for each pair of 
consecutive years separately. Given that we have 27 years of data (see Section 2) this means we estimate 26 bivariate probit models.

The estimates $\hat{\beta}_{t-1}, \hat{\beta}_{t}, \hat{\gamma}_{t-1}$ and $\hat{\gamma}_{t}$ are used to obtain $\hat{M}_{i t-1}=X_{i t-1} \hat{\beta}_{t-1}+\bar{X}_{i} \hat{\gamma}_{t-1}$ and $\hat{M}_{i t}=X_{i t} \hat{\beta}_{t}+\bar{X}_{i} \hat{\gamma}_{t}$. Together with the estimate $\hat{\rho}_{t}$ we obtain estimates of the correction terms. These are substituted in equation (11):

$$
\Delta V_{i t}=\Delta X_{i t} \beta+\pi_{t} \Lambda_{t}\left(\hat{M}_{i t-1}, \hat{M}_{i t}, \hat{\rho}_{t}\right)-\pi_{t-1} \Lambda_{t-1}\left(\hat{M}_{i t-1}, \hat{M}_{i t}, \hat{\rho}_{t}\right)+\xi_{i t} .
$$

In the second step equation (13) is estimated using a Least Squares estimator on the sub-sample of all pairs of observations for which $V_{i t-1}>0$ and $V_{i t}>0$, i.e. where we observe positive values of overtime hours in two consecutive years. Clustering is taken into account when calculating the standard errors. This two-step procedure yields consistent estimates of $\beta$ under the assumption that the explanatory variables are independent of the error terms in equations (12) and (13). The parameters $\pi_{t-1}$ and $\pi_{t}$ are treated as auxiliary parameters. In our empirical analysis we have 27 years of data, which implies we have ( 2 x 26) additional selection terms $(t=1976-2001)$.

Applied to the analysis of paid overtime, the econometric model of equation (13) extends the models chosen by Bell and Hart (1998) and Hunt (1999) by controlling for the censoring of paid overtime hours at zero. Both Bell and Hart (1998) and Hunt (1999) impose on equation (13) the restriction that $\pi_{t-1}$ and $\pi_{t}$ are each equal to zero. We test these restrictions to assess whether or not taking the censoring into account is of empirical importance. In addition to setting $\pi_{t-1}$ and $\pi_{t}$ each equal to zero, Bell and Hart (1998) in essence estimate equation (13) using all observations, i.e. including those with zero overtime hours. 


\section{Empirical results}

In this Section we analyse the extent to which paid overtime work (incidence and hours) is affected by observed characteristics. As explanatory variables we include standard working hours, basic wage rate, union coverage, recent job change (tenure less than one year), occupation, and the industry and regional location of the firm where the individual is employed. For women we also include an indicator of whether she works part-time. Sections 4.1 and 4.2 discuss the estimation results and perform sensitivity analyses for overtime incidence and hours respectively. Section 4.3 examines the extent to which changes in the observable characteristics explain the actual changes observed over the period 1975-2001.

\subsection{The incidence of paid overtime}

Table 2 reports the results from estimation of the first-stage model of the incidence of paid overtime, as outlined in Section 3.1. The estimates are presented as the marginal effects on the probability of working paid overtime.

Table 2 shows that a reduction of one hour in standard hours increases the probability of working paid overtime by 0.0067 for men and 0.0033 for women. This is significantly lower than the effects predicted by Hunt (1999) using German data: 0.029 for men working in manufacturing \& construction and 0.017 for men working in services. Hunt's model does not include any explanatory variables apart from year dummies. When we replicate the specification in Hunt (1999) we still find significantly lower effects: a one-hour reduction in standard hours reduces overtime incidence by 0.0073 for men working in manufacturing \& construction and by 0.0036 for men working in services (full set of results not reported here). For women, after controlling for standard hours, the effect of working part-time is insignificant. The wage rate has a significant negative effect on the incidence of overtime for both men and women: a onepercent increase in the basic wage rate decreases the incidence of overtime by $0.068 \%$ for men and 
$0.0103 \%$ for women. Union coverage increases the incidence of overtime for men by 0.0082 , but has an insignificant effect for women. This conclusion contrasts, in both magnitude and direction, with the finding by Trejo (1993) that, for hourly paid workers in the US, unionisation (defined as covered workers plus union members) reduces overtime incidence by $17 \%$. However, when Trejo adds a control for the probability that an overtime premium is paid, the effect of union coverage becomes insignificant and more in line with our results. This may indicate that unobservable characteristics do matter and failure to control for them may affect the parameter estimates. We return later to this issue. A further possibility is that the NESPD question, restricting coverage to specified major national or industry level agreements, is a weak measure of the role of union coverage. Recent job-change has no effect on overtime incidence for men, but for women it lowers the probability of working overtime by 0.0024 . As mentioned in Section 3, age effects are not identified.

The role of occupation as a determinant of overtime working is clearly established in Table 2. Plant and machine operatives (semi-skilled manual workers - the reference category) are more likely than other occupations to work overtime. Blue collar workers are more likely to work overtime than white collar workers, with managers and professionals the least likely (although, of course, the latter group are most likely to work unpaid overtime - see Section 1). For women the differences across occupations are still significant but smaller. Estimates of the industry effects show that especially employees in the transport sector, both men and women, have a relatively high incidence of overtime, while the education sector makes conspicuously little use of paid overtime. Regional differences are jointly insignificant for men and only marginally significant for women.

A further empirical issue with a linear probability model is that the predicted individual probabilities may lie outside the zero-one interval in small samples. On checking, our relatively large sample did not reveal any unusually large predicted changes in the individual probabilities of working overtime that would cause the probability to lie outside the zero-one interval. 
Previous studies, with the exception of Hunt (1999) as discussed above, use econometric models that do not control for unobserved individual specific effects that are allowed to correlate with the explanatory variables. Most often this is due to data limitations. As a sensitivity analysis on this aspect of specification Table 3 reports estimates using a random effects estimator, as employed by Bauer and Zimmermann (1999) and in essence also Trejo (1993) since he estimates equation (1) on a single crosssection. A formal test of a random versus a fixed effects model, or rather a general model specification test, is the well-known Hausman test (Hausman, 1978). The Hausman test statistics reported at the bottom of Table 3 show that the random effects specification is clearly rejected by the data. This indicates that estimates using a random effects estimator will be biased and any inferences based on a cross-section model or random effects panel data model have to be made with extreme caution. The estimates in Table 3 can be compared with those at the top of Table 2 to give insights into the empirical importance of controlling for unobserved individual specific effects that are allowed to correlate with the explanatory variables. For men and women, the random effects specification biases the estimated effect of standard hours on overtime incidence upwards (i.e. smaller negative). This may explain why Bauer and Zimmermann (1999), for Germany, find that lower standard hours reduce overtime. For men, the random effects specification overestimates the effect of basic pay on overtime incidence by a factor of two; for women, the absolute bias is smaller but switches sign. The effect of union coverage is overestimated for both men and women. In a random effects model the effect of age on overtime incidence is identified because orthogonality is assumed between age and the unobserved individual specific effect; implicitly, also, there are no birth-cohort effects. Clearly, since this model is rejected one cannot interpret the estimates of the age effects. The overall conclusion is that using a random effects specification yields severely biased parameter estimates.

\subsection{Paid overtime hours}


The results are reported in Table 4 for the second stage of the model as outlined in Section 3.2. The estimates are interpreted as the marginal effects on paid overtime hours when working overtime. At the bottom of Table 4 we report on a joint test of the significance of the parameters corresponding to the correction terms for positive hours of overtime in equation (13). In the equation for men we reject the nullhypothesis that all the $\pi_{t-1}$ 's and $\pi_{t}$ 's are equal to zero, although we do not reject it for women. We return to this when discussing Table 5 below.

Table 4 shows that a one-hour reduction in standard hours increases overtime hours by 0.13 hours for men and 0.16 hours for women, both significant. This negative effect is in line with theoretical predictions and with the effect on overtime incidence. Hunt (1999), however, estimates an insignificant effect for men working in manufacturing \& construction and a 0.38 hours increase for men working in services. Using exactly the same specification as Hunt we still find significantly different effects: a onehour reduction in standard hours brings a 0.20 hours increase in overtime for men employed in manufacturing \& construction and 0.15 hours increase for men in services. Bell and Hart (1999a), using cross section NES data for men in 1996, report that a one-hour reduction in standard hours results in a 0.087 increase in overtime hours, about two-thirds of our estimate. The effects of the hourly wage on overtime hours suggest a dominating effect from labour supply. A $1 \%$ increase in the basic wage rate increases overtime hours by 0.0105 hours for men and 0.0017 hours for women (Table 4). In contrast to our findings Bell and Hart (1998, 1999a) report a (small) decrease in overtime hours. For the US, Trejo (1993) also reports a positive effect. We find that union coverage does not significantly reduce overtime hours; this is in line with Bell and Hart (1998, p.346) and Trejo (1993, Table 9). A recent job change does not significantly affect overtime hours.

For both men and women the estimates of occupation, industry and region effects are often insignificant. Occupational differences are jointly insignificant for men but jointly significant for women. Industry differences are jointly significant for men but jointly insignificant for women. Regional differences 
are jointly insignificant for both men and women. The main significant differences are: men in Health services and in Distributive trades work relatively fewer overtime hours, and women working as Managers and Professionals work relatively fewer overtime hours.

Direct comparison of our results with those obtained in other studies is limited by the different econometric methods used. To gain some insights into this issue we report in Table 5 the results we would obtain applying the differing econometric methodologies suggested in Trejo (1993), Bell \& Hart (1998, 1999a), Hunt (1999) and Bauer and Zimmermann (1999). We cannot adopt their models exactly, and there are some minor differences such as our use of a first-difference estimator instead of a fixed effects 'within' estimator. But the underlying assumptions we make in estimating these alternative models are the same as in the originals, or even slightly less stringent, making the comparison favourable to their alternative approaches. In spite of these caveats, the exercise is extremely useful from a methodological point of view. The results of Table 5 compare with those at the top of Table 4 .

Bell and Hart (1998) and Hunt (1999, Table 1, first columns) essentially estimate the main equation in first differences using all observations, setting overtime hours to zero for those who do not work overtime. This is the first column of results in Table 5. The effect of standard hours does not change much for men but is substantially overestimated (i.e. smaller negative) for women $(-0.042$ versus -0.155$)$. The effects of basic pay are severely biased and even switch signs. The same holds for union coverage. Overall we conclude that the approach of taking first-differences of overtime hours (or, by extension, total hours) without controlling for the censoring of overtime hours at zero yields severely biased estimates.

Column 2, Table 5, reports the estimation results when we take first-differences of overtime hours for those who work overtime in two consecutive years, but without controlling for sample selection, i.e. equation (13) with $\pi_{t-1}=\pi_{t}=0$. Hunt (1999, Table 1, last column) also estimates this model. As discussed above, for women taking into account censoring of overtime hours at zero turns out to be of no empirical importance when estimating the model in first-differences. Hence it is not surprising that we find that for 
women the results in Table 4 and Table 5, second column, are not significantly different from each other. For men the results are significantly different; in particular, the effect of the wage rate is severely underestimated. Hence, we conclude that controlling for the censoring of overtime hours at zero is of empirical importance.

The third column reports on random effects Tobit estimates, hence assuming there are no correlations between the unobserved individual specific effects and the explanatory variables. Here we use a two-step estimator (Heckman, 1976). The Hausman test statistics are reported in the bottom rows. For both men and women we reject the random effects model. When comparing the estimates of Table 5, third column, with those in Table 4 one has to conclude that estimates of the parameters of interest in this study based on a single cross-section or a random effects specification when using panel data are severely biased.

\subsection{Predictions}

The results above suggest that most of the included explanatory variables have significant but small effects on overtime work. Table 6 quantifies their estimated impact on changes in overtime incidence and hours for those working overtime over the observation period 1975-2001. For these within sample predictions the observed changes in the explanatory variables (in parentheses, Table 6) are used together with the parameter estimates of Tables 2 and 4.

Table 6, Panel A, shows that for men the model can explain $43 \%$ of the observed change in overtime incidence from 1975-2001. The actual decrease in standard hours of 0.8 hours resulted in an increase in the incidence of overtime of 0.51 percentage points. The largest contributions to the observed decline in overtime incidence came from basic pay, where the $50 \%$ increase over the period brought a reduction of $3.43 \%$-points, and changes in the occupational and industry structure of employment, bringing a further decrease of $2.45 \%$-points. For women the model is much less successful, predicting a small 
decrease of $0.52 \%$ in overtime incidence, against the actual increase of $7.4 \%$. The rise in basic pay and the changing occupational and industry structure of employment all predict a fall in the incidence of overtime, with only standard hours tending to increase it. The actual increase in overtime incidence for women effectively remains unexplained. For overtime hours the relative predictive performance for men and women is reversed. For women the model predicts an increase in overtime hours worked of 0.17, against an actual increase of 0.21 , with the largest contribution again coming from the reduction in standard hours. For men, on the other hand, the model predicts a small increase of 0.70 in overtime hours, with almost all the variables identified contributing to an increase, while the recorded change was a decline of 1.42 hours.

These results suggest that there are further influences on both overtime incidence and hours not captured in our model. In the case of overtime working by women we have not been able to control for employment participation. As discussed in Section 2, being employed is a condition for being in the sample. Since the employment decision will be influenced by the wage, the estimated coefficients are likely to be biased. Economic analyses point to the overtime premium and fixed costs of employment (such as personnel costs and training expenditures) as further determinants of overtime work, neither of which are available in our data. We also note the changes in contractual work patterns that are occurring, such as the shift to more flexible hours across workweeks, including the use of annualised hours. Where these are not constant for the individual worker in consecutive periods and are correlated with the included variables omitted variable bias will occur. So while we are confident that our estimates improve on earlier studies by reducing the various biases we have identified, other potential sources of bias remain to be addressed.

\section{Conclusions}


This paper has investigated the use of paid overtime work in Britain using individuatlevel data from the New Earnings Survey from 1975-2001. A panel data model has been employed allowing for censoring of paid overtime hours at zero and for correlations between the explanatory variables and unobserved individual specific effects. In particular we have examined the effects of standard working hours, the basic wage rate and unionisation, as well as the occupational and industrial structure of employment, on paid overtime incidence and on hours conditioned on working overtime. The main empirical findings are summarized as follows:

(i) Over this 27-year period paid overtime working was a major and persistent feature of employment. Over $40 \%$ of men were working paid overtime in the Survey week each year until 1990, and in 2000 the proportion was still 32\%. Among women, the incidence was lower, but rising quite sharply, from $10 \%$ to around $18 \%$. For those working overtime the hours involved are substantial: 7-9 hours per week on average for men and 3-4 hours for women.

(ii) A reduction in standard weekly hours increases paid overtime work, both incidence and hours; this is the case for women as well as for men. An increase in the wage rate decreases the incidence of overtime, but slightly increases overtime hours for those working overtime. These wage effects are stronger for men than for women. Union coverage emerges as of minor empirical importance in spite of its dramatic decline. The occupation and industry structure of employment have been changing away from high overtime jobs towards occupations and industries where less paid overtime is worked. Although many of these effects are statistically significant their practical effects tend to be relatively small. Taken together, these economic variables can explain almost half of the change in the incidence of overtime for men, and most of the change in overtime hours worked by women. However, they are less successful in explaining the change in overtime hours worked by men or the change in the incidence of overtime for women. 
(iii) Our main analytical conclusion concerns the appropriate econometric model for analysing overtime hours. We find evidence that the effects identified in previous studies may be seriously biased (Table 2 versus Table 3, and Table 4 versus Table 5). We conclude therefore that it is of major empirical importance to use an econometric framework that controls for both the censoring of paid overtime hours at zero and the correlation between explanatory variables and unobserved individual specific effects. 


\section{Acknowledgements}

Financial support from the Leverhulme Trust project "The labour market consequences of technical and structural change" is gratefully acknowledged. We wish to thank the seminar participants at the Leverhulme Trust project meeting at the University of Essex, the 2000 Annual Conference of the Royal Economic Society at the University of St. Andrews, the Centre for Economic Performance (CEP) at the London School of Economics, the Institute for the Study of Labor (IZA) in Bonn, the EALE-SOLE joint meeting in Milan, the Applied Econometrics Association in Helsinki, the Tinbergen Institute at the University of Amsterdam, University of Cardiff and the Labour Economics seminar at the University of Oxford. The editor Peter Lynn, the associate editor and two anonymous referees provided extremely useful comments and discussion.

\section{References}

Bauer, T. and Zimmermann, K.F. (1999) Overtime work and overtime compensation in Germany, Scottish Journal of Political Economy, 46, 419-436.

Beatson, M. (1995) Labour Market Flexibility, Research Series no. 48, Department of Employment, London.

Bell, D.N.F. and Hart, R.A. (1998) Working time in Great Britain, 1975-1994, Journal of the Royal Statistical Society, Series A, 161 (3), 327-348.

Bell, D.N.F. and Hart, R.A. (1999) Unpaid work, Economica, 66, 271-290.

Bell, D.N.F. and Hart, R.A. (1999a) Overtime working in an unregulated labor market, IZA Discussion Paper, no. 44, Institute for the Study of Labor, Bonn. 
Calmfors, L. and Hoel, M. (1988) Worksharing and overtime, Scandinavian Journal of Economics, 90 (1), 45-52.

Contensou. F. and Vranceanu, R. (2000) Working time in a trade union model, chapter 10 in: Working Time: Theory and Policy Implications, Edward Elgar, Cheltenham.

Hamermesh, D.S. (1993) Labor Demand, Princeton University Press, Chichester, West-Sussex.

Hart, R.A. (1987) Working Time and Employment, Allen and Unwin, London.

Hausman, J.A. (1978) Specification tests in econometrics, Econometrica, 46 (6), 1251-1271.

Heckman, J.J. (1976) The common structure of statistical models of truncation, sample selection and limited dependent variables and a simple estimator for such models, Annals of Economic and Social Measurement, 5, 475-492.

Heckman, J.J. and Robb R. (1985) Using longitudinal data to estimate age, period and cohort effects in earnings equations, pp. 137-150 in W.M. Mason and S.E. Fienberg (eds.), Cohort Analysis in Social Research: Beyond the Identification Problem, Springer-Verlag: New York

Honoré, B.E. (2002) Nonlinear models with panel data, Portuguese Economic Journal, 1 (2), 163-179.

Hunt, J. (1999) Has work-sharing worked in Germany?, The Quarterly Journal of Economics, 117-148.

Kalwij, A.S. (2003) A Maximum Likelihood Estimator based on first differences for a panel data Tobit model with individual specific effects, Economics Letters, 81 (2), 19-26.

Kalwij, A.S. (2003a) A two-step first-difference estimator for a panel data Tobit model, working paper, Department of Economics, University of Amsterdam (http://www.uvaaias.net/files/working_papers/WP21).

Kalwij, A.S. and Alessie, R. (2003) Permanent and transitory wage inequality of British men, 1975-2001: year, age and cohort effects, working paper, University of Amsterdam. 
Lilien, D.M. and Hall, R.E. (1986) Cyclical fluctuations in the labor market, Chapter 17 in Handbook of Labor Economics, Vol.II, editors: O.Ashenfelter and R. Layard, Elsevier Science Publishers, Amsterdam.

Mundlak, Y. (1978) On the pooling of time series and cross section data, Econometrica, 46, 69-86.

Nickell, S.J. (1983) Working hours in Britain, Working Paper no. 565, Centre for Labour Economics, London School of Economics.

Pencavel, J. (1986) Labor supply of men: a survey, Chapter 1 in Handbook of Labor Economics, Vol.I, editors: O.Ashenfelter and R. Layard, Elsevier Science Publishers, Amsterdam.

Rochina-Barrachina, M.E. (1999) A new estimator for panel data sample selection models, Annales d'Économie et de Statistique, 55/56, 153-181.

Sallis, H. (1970) Overtime in electricity supply: its incidence and control in England and Wales 1954-1969, Occasional Paper, British Journal of Industrial Relations.

Tobin, J. (1958) Estimation of relationships for limited dependent variables, Econometrica, 26, 24-36.

Trejo, S.J. (1991) The effects of overtime pay regulation on worker compensation, American Economic Review, 81 (4), 719-740.

Trejo, S.J. (1993) Overtime pay, overtime hours, and labor unions, Journal of Labor Economics, 11 (2), 253-278.

Trejo, S.J. (2003) Does the statutory overtime premium discourage long workweeks?, Industrial and Labor Relations Review, 56 (3), 530-551.

Wooldridge, J.M. (1995) Selection corrections for panel data models under conditional mean independence assumptions, Journal of Econometrics, 68, 115-132. 
Table 1: Descriptive statistics

\begin{tabular}{lrrrrrr}
\hline Year & $\mathbf{1 9 7 5}$ & $\mathbf{1 9 8 0}$ & $\mathbf{1 9 8 5}$ & $\mathbf{1 9 9 0}$ & $\mathbf{1 9 9 5}$ & $\mathbf{2 0 0 0}$ \\
\hline Number of observations & 63245 & 91491 & 89750 & 98492 & 104850 & 102040 \\
Female share in employment $(\%)$ & 34.8 & 38.1 & 40.6 & 42.3 & 45.3 & 46.3
\end{tabular}

\section{Panel A: Men}

$\begin{array}{ll}\text { Age (years) } & \text { average } \\ \text { Union coverage } & \%\end{array}$

Job tenure less than one year, \%

Basic pay per hour (£2001)

$$
\begin{aligned}
& \text { average } \\
& \text { 10th percentile } \\
& \text { 50th percentile } \\
& \text { 90th percentile }
\end{aligned}
$$

Standard working hours (per week)

$$
\begin{aligned}
& \text { average } \\
& \text { 10th percentile } \\
& \text { 50th percentile } \\
& \text { 90th percentile }
\end{aligned}
$$

Part-time work (less than 30 standard hours) \%

Incidence of paid overtime (\%)

Paid overtime hours if working overtime (per week)

$$
\begin{aligned}
& \text { average } \\
& \text { 10th percentile } \\
& 50 \text { th percentile } \\
& 90 \text { th percentile }
\end{aligned}
$$

$\begin{array}{rrrrrr}39.5 & 39.7 & 39.0 & 38.7 & 38.7 & 39.8 \\ 57.9 & 48.4 & 48.0 & 34.8 & 26.7 & 17.6 \\ 13.6 & 13.3 & 9.8 & 16.7 & 13.2 & 13.7\end{array}$

$\begin{array}{rrrrrr}7.6 & 7.8 & 8.6 & 9.7 & 10.6 & 11.4 \\ 4.9 & 4.8 & 4.9 & 5.2 & 5.2 & 5.6 \\ 6.9 & 7.0 & 7.6 & 8.4 & 9.0 & 9.6 \\ 11.2 & 11.9 & 13.8 & 16.1 & 18.0 & 19.5\end{array}$

\begin{tabular}{rrrrrr}
38.8 & 38.5 & 38.0 & 38.1 & 38.1 & 38.1 \\
36.0 & 35.0 & 35.0 & 35.0 & 35.0 & 35.0 \\
40.0 & 40.0 & 38.0 & 37.8 & 37.5 & 37.5 \\
40.0 & 40.0 & 40.0 & 40.0 & 40.0 & 41.5 \\
& & & & & \\
0.1 & 0.2 & 0.2 & 0.2 & 1.8 & 2.3 \\
& & & & & \\
45.3 & 42.0 & 42.3 & 42.8 & 36.0 & 32.1 \\
& & & & & \\
8.5 & 8.7 & 8.2 & 8.6 & 8.3 & 7.1 \\
1.9 & 1.8 & 1.5 & 1.5 & 1.3 & 0.6 \\
7.4 & 7.5 & 7.0 & 7.1 & 6.5 & 5.4 \\
17.5 & 18.0 & 17.1 & 18.2 & 18.3 & 16.4 \\
& & & & & \\
\hline
\end{tabular}


Table 1: continued.

\begin{tabular}{lllllll}
\hline Year & 1975 & 1980 & 1985 & 1990 & 1995 & 2000 \\
\hline
\end{tabular}

\section{Panel B: Women}

$\begin{array}{ll}\text { Age (years) } & \text { average } \\ \text { Union coverage } & \%\end{array}$

Job tenure less than one year, $\%$

Basic pay per hour (£ 2001)

$$
\begin{aligned}
& \text { average } \\
& \text { 10th percentile } \\
& \text { 50th percentile } \\
& \text { 90th percentile }
\end{aligned}
$$

Standard working hours (per week)

$$
\begin{aligned}
& \text { average } \\
& \text { 10th percentile } \\
& \text { 50th percentile } \\
& \text { 90th percentile }
\end{aligned}
$$

Part-time work (less than 30 standard hours) \%

Incidence of paid overtime(\%)

Paid overtime hours if working overtime (per week)

average
10th percentile
50th percentile
90th percentile

$\begin{array}{llllll}40.0 & 40.0 & 38.7 & 38.2 & 38.5 & 39.7 \\ 57.2 & 52.8 & 56.3 & 44.5 & 37.3 & 34.4 \\ 17.5 & 14.6 & 11.4 & 20.2 & 14.7 & 15.7\end{array}$

$\begin{array}{rrrrrr}5.3 & 5.4 & 5.9 & 7.0 & 7.9 & 8.5 \\ 3.4 & 3.5 & 3.6 & 3.9 & 4.1 & 4.4 \\ 4.8 & 4.8 & 5.3 & 6.1 & 6.7 & 7.3 \\ 7.7 & 8.0 & 9.2 & 11.5 & 13.4 & 14.6\end{array}$

$\begin{array}{llllll}32.4 & 31.2 & 31.0 & 31.4 & 31.0 & 30.6\end{array}$

$\begin{array}{llllll}20.0 & 18.0 & 17.0 & 17.5 & 16.5 & 16.0\end{array}$

$\begin{array}{llllll}36.0 & 35.0 & 35.0 & 35.0 & 35.0 & 35.0\end{array}$

$\begin{array}{llllll}40.0 & 40.0 & 39.0 & 39.0 & 39.0 & 39.0\end{array}$

$\begin{array}{llllll}29.9 & 34.7 & 32.6 & 30.9 & 32.8 & 36.0\end{array}$

$\begin{array}{llllll}10.2 & 10.1 & 15.9 & 18.9 & 19.8 & 17.6\end{array}$

$\begin{array}{llllll}3.4 & 3.6 & 3.6 & 3.9 & 3.9 & 3.6\end{array}$

$\begin{array}{llllll}0.5 & 0.5 & 0.5 & 0.6 & 0.6 & 0.3\end{array}$

$\begin{array}{llllll}2.5 & 2.8 & 2.5 & 2.8 & 2.8 & 2.5\end{array}$

\begin{tabular}{llllll}
7.5 & 8.0 & 8.0 & 8.8 & 9.0 & 8.4 \\
\hline
\end{tabular}


Table 2: Estimation results: equation (2). Time effects are included. The dependent variable is the change in the incidence of paid overtime.

\begin{tabular}{|c|c|c|c|c|}
\hline \multirow{2}{*}{$\begin{array}{l}\text { Marginal effects on incidence of paid overtime } \\
\text { Explanatory variables }\end{array}$} & \multicolumn{2}{|c|}{ Men } & \multicolumn{2}{|c|}{ Women } \\
\hline & p.e. & s.e. & p.e. & s.e. \\
\hline Part-time & & & -0.0010 & 0.0033 \\
\hline Standard hours & -0.0067 & 0.0003 & -0.0033 & 0.0002 \\
\hline Log-hourly basic pay & -0.0680 & 0.0034 & -0.0103 & 0.0033 \\
\hline Union coverage & 0.0082 & 0.0019 & -0.0002 & 0.0020 \\
\hline Job tenure less than one year & 0.0004 & 0.0012 & -0.0024 & 0.0011 \\
\hline Age squared & $-1.8 \mathrm{E}-04$ & $1.3 \mathrm{E}-05$ & $-8.4 \mathrm{E}-06$ & $1.2 \mathrm{E}-05$ \\
\hline \multicolumn{5}{|l|}{ Occupation } \\
\hline Managers and administrators & -0.1226 & 0.0064 & -0.0583 & 0.0101 \\
\hline Professional & -0.0906 & 0.0067 & -0.0424 & 0.0103 \\
\hline Associate professional/ technical & -0.0881 & 0.0070 & -0.0558 & 0.0100 \\
\hline Clerical and secretarial & -0.0648 & 0.0066 & -0.0416 & 0.0092 \\
\hline Craft and related occupations & -0.0216 & 0.0058 & -0.0225 & 0.0114 \\
\hline Personal and protective services & -0.0199 & 0.0102 & -0.0486 & 0.0099 \\
\hline Sales & -0.1332 & 0.0077 & -0.0236 & 0.0100 \\
\hline Plant and machine operatives & 0 & - & 0 & - \\
\hline Other & -0.0186 & 0.0076 & -0.0554 & 0.0099 \\
\hline \multicolumn{5}{|l|}{ Industry } \\
\hline Agriculture & -0.0525 & 0.0218 & 0.0088 & 0.0322 \\
\hline Energy and water supply & -0.0253 & 0.0138 & 0.0530 & 0.0181 \\
\hline Mineral extractions, metal and chemical products & 0.0033 & 0.0093 & 0.0062 & 0.0114 \\
\hline Metal goods and engineering products & 0.0074 & 0.0076 & 0.0296 & 0.0089 \\
\hline Other manufacturing industries & 0 & - & 0 & - \\
\hline Construction & -0.0065 & 0.0096 & -0.0081 & 0.0118 \\
\hline Distributive trades and catering & -0.0270 & 0.0073 & 0.0173 & 0.0071 \\
\hline Transport and communications & 0.0484 & 0.0099 & 0.0406 & 0.0118 \\
\hline Financial services & -0.0281 & 0.0079 & 0.0116 & 0.0073 \\
\hline Public administration & -0.0438 & 0.0102 & -0.0054 & 0.0085 \\
\hline Educational services & -0.0822 & 0.0128 & -0.0273 & 0.0084 \\
\hline Health services & -0.0175 & 0.0167 & -0.0094 & 0.0088 \\
\hline Business and other services & -0.0402 & 0.0100 & 0.0018 & 0.0080 \\
\hline
\end{tabular}

Table 2 continues on the next page 
Table 2: Continued

\begin{tabular}{|c|c|c|c|c|}
\hline \multicolumn{5}{|l|}{ Region } \\
\hline Greater London & 0 & - & 0 & - \\
\hline South-East (excluding Greater London) & 0.0032 & 0.0062 & 0.0157 & 0.0070 \\
\hline East Anglia & -0.0059 & 0.0131 & 0.0179 & 0.0153 \\
\hline South West & -0.0046 & 0.0102 & 0.0497 & 0.0121 \\
\hline West Midlands & -0.0031 & 0.0103 & 0.0116 & 0.0125 \\
\hline East Midlands & 0.0053 & 0.0111 & -0.0073 & 0.0134 \\
\hline Yorkshire \& Humberside & -0.0111 & 0.0108 & 0.0060 & 0.0128 \\
\hline North West & -0.0152 & 0.0107 & -0.0036 & 0.0123 \\
\hline North & 0.0077 & 0.0166 & 0.0299 & 0.0165 \\
\hline Wales & -0.0017 & 0.0163 & 0.0245 & 0.0177 \\
\hline Scotland & 0.0195 & 0.0144 & 0.0116 & 0.0159 \\
\hline $\mathrm{N}$ & 1177724 & & 826702 & \\
\hline $\mathrm{R}^{2}$ & 0.0044 & & 0.0024 & \\
\hline
\end{tabular}

Table 3: Sensitivity analysis: estimation of equation (1) with $\mu_{i}$ treated as a random individual specific effect (specification of Bauer and Zimmermann, 1999)."

\begin{tabular}{|c|c|c|c|c|}
\hline \multirow{2}{*}{$\begin{array}{l}\text { Dependent variable: } \\
\text { incidence of paid overtime }\end{array}$} & \multirow{2}{*}{$\begin{array}{c}\text { Men } \\
\text { p.e. }\end{array}$} & \multicolumn{3}{|c|}{ Women } \\
\hline & & s.e. & p.e. & s.e. \\
\hline Age & 0.0135 & 0.0005 & 0.0063 & 0.0024 \\
\hline Part-time & & & -0.0009 & 0.0004 \\
\hline Standard hours & -0.0041 & 0.0002 & -0.0007 & 0.0001 \\
\hline Log-hourly basic pay & -0.1495 & 0.0023 & 0.0086 & 0.0020 \\
\hline Union coverage & 0.0315 & 0.0019 & -0.0045 & 0.0015 \\
\hline Job tenure less than one year & 0.0016 & 0.0014 & 0.0043 & 0.0013 \\
\hline Age squared & $-1.7 \mathrm{E}-04$ & $6.5 \mathrm{E}-06$ & $-4.4 \mathrm{E}-06$ & $5.0 \mathrm{E}-06$ \\
\hline $\mathrm{N}$ & 1177724 & & 826702 & \\
\hline $\mathrm{R}^{2}$ & 0.1629 & & 0.0362 & \\
\hline
\end{tabular}

Hausman model missspecification test. (Null-hypothesis: no misspecification) $88.2^{\mathrm{a}}$ $19.3^{\mathrm{b}}$

* Controls are also included for the year of observation, the individual's occupation, and the industry and region of the firm at which employed.

${ }^{\text {a }}$ Critical Value is $\mathrm{F}(36,8)=1.93$.

${ }^{\mathrm{b}}$ Critical Value is $\mathrm{F}(37,8)=1.91$. 
Table 4: Estimation results: equation (13). Time effects are included. The dependent variable is the change in weekly paid overtime hours

\begin{tabular}{|c|c|c|c|c|}
\hline \multirow{2}{*}{$\begin{array}{l}\text { Effects on Paid Overtime Hours } \\
\text { Explanatory variables }\end{array}$} & \multicolumn{2}{|c|}{ Men } & \multicolumn{2}{|l|}{ Women } \\
\hline & p.e. & s.e. & p.e. & s.e. \\
\hline Part-time & & & -0.1630 & 0.1662 \\
\hline Standard hours & -0.1305 & 0.0110 & -0.1553 & 0.0108 \\
\hline Log-hourly basic pay & 1.0534 & 0.1138 & 0.1714 & 0.1597 \\
\hline Union coverage & -0.0859 & 0.0464 & 0.1052 & 0.0692 \\
\hline Job tenure less than one year & 0.0411 & 0.0319 & 0.0670 & 0.0363 \\
\hline Age squared & -0.0013 & 0.0004 & -0.0010 & 0.0006 \\
\hline \multicolumn{5}{|l|}{ Occupation } \\
\hline Managers and administrators & 0.2909 & 0.2023 & -1.2319 & 0.3379 \\
\hline Professional & -0.0844 & 0.1917 & -1.1612 & 0.3348 \\
\hline Associate professional/ technical & -0.2639 & 0.1938 & -1.4791 & 0.3655 \\
\hline Clerical and secretarial & -0.2987 & 0.1526 & -1.3651 & 0.3035 \\
\hline Craft and related occupations & -0.1130 & 0.1255 & -0.3376 & 0.3585 \\
\hline Personal and protective services & 0.0435 & 0.2764 & -0.5692 & 0.4059 \\
\hline Sales & 0.4237 & 0.2647 & -1.3703 & 0.3595 \\
\hline Plant and machine operatives & 0 & - & 0 & - \\
\hline Other & 0.0513 & 0.1638 & -0.6247 & 0.4122 \\
\hline \multicolumn{5}{|l|}{ Industry } \\
\hline Agriculture & -0.3942 & 0.5836 & 0.0168 & 0.9727 \\
\hline Energy and water supply & -0.6269 & 0.4322 & 0.2630 & 0.7232 \\
\hline Mineral extractions, metal and chemical products & -0.7342 & 0.2681 & 0.5121 & 0.6857 \\
\hline Metal goods and engineering products & -0.8878 & 0.2068 & 0.2321 & 0.4018 \\
\hline Other manufacturing industries & 0 & - & 0 & - \\
\hline Construction & -0.5686 & 0.2652 & 0.2483 & 0.7304 \\
\hline Distributive trades and catering & -0.9171 & 0.2284 & -0.2704 & 0.3756 \\
\hline Transport and communications & 0.2251 & 0.2637 & 0.0785 & 0.4965 \\
\hline Financial services & -0.5391 & 0.3033 & -0.4557 & 0.3803 \\
\hline Public administration & -0.8392 & 0.3364 & 0.1377 & 0.5086 \\
\hline Educational services & 0.4137 & 0.5756 & 0.5419 & 0.5828 \\
\hline Health services & -1.8958 & 0.6685 & -0.3728 & 0.5662 \\
\hline Business and other services & -0.3445 & 0.3623 & 0.0258 & 0.4525 \\
\hline
\end{tabular}

Table 4 continues on the next page. 
Table 4: Continued

\begin{tabular}{|c|c|c|c|c|}
\hline \multicolumn{5}{|l|}{ Region } \\
\hline Greater London & 0 & - & 0 & - \\
\hline South-East (excluding Greater London) & -0.2059 & 0.2792 & -0.2558 & 0.2742 \\
\hline East Anglia & -0.3961 & 0.5545 & -0.0191 & 0.5961 \\
\hline South West & -0.9085 & 0.4219 & 0.4074 & 0.4953 \\
\hline West Midlands & -0.2865 & 0.4437 & 0.0452 & 0.4951 \\
\hline East Midlands & -0.5221 & 0.4387 & 0.3820 & 0.5628 \\
\hline Yorkshire \& Humberside & -0.5069 & 0.4537 & 0.5372 & 0.4284 \\
\hline North West & -0.4390 & 0.4571 & 0.1017 & 0.5320 \\
\hline North & 0.8069 & 0.6250 & 0.0422 & 0.8575 \\
\hline Wales & 0.2985 & 0.6266 & 0.9273 & 0.6171 \\
\hline Scotland & -0.2800 & 0.5744 & 0.4068 & 0.6419 \\
\hline $\mathrm{N}$ & 346909 & & 72077 & \\
\hline $\mathrm{R}^{2}$ & 0.0083 & & 0.0219 & \\
\hline F-test on the sample correction terms & $6.97^{\mathrm{a}}$ & & $1.37^{\mathrm{a}}$ & \\
\hline
\end{tabular}

${ }^{\mathrm{a}}$ Critical Value is $\mathrm{F}(52,8)=1.89$. 
Table 5: Sensitivity analysis: comparison with estimates obtained using the methodology of previous studies. The dependent variable is weekly paid overtime hours for those working overtime.*

\begin{tabular}{|c|c|c|c|c|c|c|}
\hline \multirow[t]{3}{*}{ Cells: Marginal Effects } & \multirow{2}{*}{\multicolumn{2}{|c|}{$\begin{array}{c}\begin{array}{c}\text { First-difference } \\
\text { all observations }\end{array} \\
\text { Bell \& Hart (1998) } \\
\text { Hunt (1999) } \\
\end{array}$}} & \multicolumn{2}{|c|}{$\begin{array}{c}\text { First-difference } \\
\text { if working overtime }\end{array}$} & \multirow{2}{*}{\multicolumn{2}{|c|}{$\begin{array}{c}\begin{array}{c}\text { Random Effects } \\
\text { Tobit }\end{array} \\
\text { Trejo (1993) } \\
\text { Bell \& Hart (1999) } \\
\text { Bauer \& Zimmermann (1999) } \\
\end{array}$}} \\
\hline & & & Hunt (199 & & & \\
\hline & p.e. & s.e. & p.e. & s.e. & p.e. & s.e. \\
\hline$\overline{\text { Age }}$ & & & & & 0.2909 & 0.0131 \\
\hline Standard hours & -0.1196 & 0.0039 & -0.1660 & 0.0104 & -0.0245 & 0.0083 \\
\hline Log-hourly basic pay & -0.5882 & 0.0474 & 0.4400 & 0.1016 & -1.3564 & 0.1017 \\
\hline Union coverage & 0.0944 & 0.0233 & 0.0154 & 0.0452 & -0.2856 & 0.0436 \\
\hline Job tenure less than one year & 0.0292 & 0.0133 & 0.0224 & 0.0316 & 0.2026 & 0.0408 \\
\hline Age squared & -0.0024 & 0.0001 & -0.0024 & 0.0004 & -0.0034 & 0.0002 \\
\hline $\mathrm{N}$ & 1177724 & & 346909 & & 346909 & \\
\hline $\mathrm{R}^{2}$ & 0.0061 & & 0.0072 & & 0.0760 & \\
\hline $\begin{array}{l}\text { Hausman model missspecication test. } \\
\text { Null-hypothesis is no misspecification }\end{array}$ & & & & & $25.70^{\mathrm{a}}$ & \\
\hline Women & p.e. & s.e. & p.e. & s.e. & p.e. & s.e. \\
\hline Age & & & & & 0.0588 & 0.0128 \\
\hline Part-time & -0.0338 & 0.0242 & -0.1671 & 0.1660 & 0.7113 & 0.1036 \\
\hline Standard hours & -0.0422 & 0.0017 & -0.1570 & 0.0107 & -0.0342 & 0.0058 \\
\hline Log-hourly basic pay & -0.0881 & 0.0266 & 0.2026 & 0.1591 & 0.1431 & 0.0725 \\
\hline Union coverage & -0.0010 & 0.0118 & 0.1009 & 0.0661 & -0.1001 & 0.0495 \\
\hline Job tenure less than one year & 0.0007 & 0.0067 & 0.0671 & 0.0360 & 0.1260 & 0.0452 \\
\hline Age squared & -0.0001 & 0.0001 & -0.0008 & 0.0005 & -0.0008 & 0.0002 \\
\hline $\mathrm{N}$ & 826702 & & 72077 & & 72077 & \\
\hline $\mathrm{R}^{2}$ & 0.005 & & 0.0208 & & 0.0962 & \\
\hline $\begin{array}{l}\text { Hausman model missspecification test. } \\
\text { Null-hypothesis is no misspecification }\end{array}$ & & & & & $4.48^{\mathrm{b}}$ & \\
\hline
\end{tabular}

* Controls are also included for the year of observation, the individual's occupation, and the industry and region of the firm at which employed.

${ }^{a}$ Critical Value is $\mathrm{F}(36,8)=1.93$.

${ }^{\mathrm{b}}$ Critical Value is $\mathrm{F}(37,8)=1.91$. 
Table 6: The predicted effects of the observed changes in characteristics on the incidence and hours of paid overtime, 1975-2001.

\begin{tabular}{lrr}
\hline Period 1975-2000 & $\begin{array}{c}\text { Predicted effect on } \\
\text { Predicted effect on } \\
\text { overtime incidence }\end{array}$ & $\begin{array}{c}\text { overtime hours conditional on } \\
\text { working overtime }\end{array}$ \\
\hline Characteristics & $\%$-points & Hours \\
\hline
\end{tabular}

Panel A: Men

Standard hours (-0.8 hours per week

0.51

0.10

Hourly basic pay $(+50 \%)$

$-3.43$

0.53

Union coverage (-40\%-points)

$-0.33$

0.03

Job tenure less than one year $(0.1 \%$-points $)$

0.00

0.00

Occupational structure

$-1.53$

0.04

Industrial structure

$-0.92$

0.02

Regional structure

$-0.01$

$-0.02$

Total explained

$-5.71$

0.70

Total change

$-13.23$

$-1.42$

Panel B: Women

Part-time (+6.1\%-points)

$-0.01$

$-0.01$

Standard hours (-1.8 hours per week)

0.60

0.28

Hourly basic pay $(+62 \%)$

$-0.64$

0.11

Union coverage (-23\%)

0.01

$-0.02$

Job tenure less than one year (-1.8\%-points)

0.00

0.00

Occupational structure

$-0.40$

$-0.12$

Industrial structure

$-0.22$

$-0.06$

Regional structure

0.14

$-0.01$

Total explained

$-0.52$

0.17

Total change

7.43

0.21 
Appendix A

Table A1: Data selection

\begin{tabular}{|c|c|c|c|c|c|c|c|c|c|c|}
\hline Year & $\begin{array}{r}\text { Raw sample } \\
\text { number of } \\
\text { observations } \\
\end{array}$ & $\begin{array}{r}\text { Missing hours } \\
\text { information }\end{array}$ & $\begin{array}{r}\text { Missing pay } \\
\text { information }\end{array}$ & $\begin{array}{l}\text { Missing } \\
\text { SIC,SOC, } \\
\text { REGION i }\end{array}$ & $\begin{array}{r}\text { Sex } \\
\text { sistent } \\
\end{array}$ & $\begin{array}{r}\text { Age } \\
\text { isten } \\
\mathrm{t} \\
\end{array}$ & $\begin{array}{r}\text { Age }<21 \\
\text { or } \\
\text { Age }>59 \\
\end{array}$ & $\begin{array}{r}\text { Top and bottom } \\
1 \text { percentile of } \\
\text { pay or hours }\end{array}$ & $\begin{array}{r}\text { No two } \\
\text { consecutive } \\
\text { observations } \\
\end{array}$ & $\begin{array}{r}\text { Final sample } \\
\text { number of } \\
\text { observations } \\
\end{array}$ \\
\hline 1975 & 157069 & 26163 & 1194 & 3865 & 2574 & 217 & 22516 & 3735 & 33560 & 63,245 \\
\hline 1976 & 169276 & 27624 & 2787 & 4148 & 2623 & 258 & 23607 & 3512 & 18099 & 86,618 \\
\hline 1977 & 172150 & 29433 & 2406 & 4130 & 2566 & 220 & 23556 & 3966 & 16349 & 89,524 \\
\hline 1978 & 172793 & 31212 & 2537 & 3836 & 2651 & 222 & 22955 & 4115 & 15999 & 89,266 \\
\hline 1979 & 173426 & 32075 & 1898 & 3222 & 2752 & 286 & 22799 & 3840 & 16673 & 89,881 \\
\hline 1980 & 172936 & 31361 & 1039 & 3228 & 2854 & 303 & 22459 & 3862 & 16339 & 91,491 \\
\hline 1981 & 173071 & 33903 & 773 & 3075 & 2815 & 263 & 21861 & 3884 & 13604 & 92,893 \\
\hline 1982 & 168178 & 30414 & 1226 & 3122 & 2743 & 227 & 20400 & 3844 & 12068 & 94,134 \\
\hline 1983 & 163623 & 28648 & 1220 & 2954 & 2657 & 265 & 18912 & 3896 & 11443 & 93,628 \\
\hline 1984 & 161969 & 29969 & 1243 & 3024 & 2634 & 263 & 17904 & 3837 & 11141 & 91,954 \\
\hline 1985 & 158212 & 29641 & 1357 & 3012 & 2870 & 251 & 16727 & 3891 & 10713 & 89,750 \\
\hline 1986 & 161319 & 28185 & 1666 & 2944 & 3414 & 275 & 17021 & 4033 & 12077 & 91,704 \\
\hline 1987 & 165831 & 31250 & 1752 & 3259 & 4247 & 267 & 16781 & 4119 & 11624 & 92,532 \\
\hline 1988 & 171704 & 31067 & 1786 & 3212 & 4150 & 284 & 17332 & 4371 & 13829 & 95,673 \\
\hline 1989 & 170792 & 30316 & 1710 & 3185 & 4449 & 362 & 16950 & 4353 & 12283 & 97,184 \\
\hline 1990 & 174373 & 33259 & 2419 & 3186 & 3327 & 522 & 16599 & 4376 & 12193 & 98,492 \\
\hline 1991 & 173090 & 32043 & 2684 & 3279 & 3910 & 474 & 15363 & 4178 & 11530 & 99,629 \\
\hline 1992 & 167161 & 32038 & 2116 & 3090 & 3901 & 372 & 13226 & 4231 & 10250 & 97,937 \\
\hline 1993 & 160584 & 29048 & 1827 & 3043 & 3346 & 548 & 11669 & 4294 & 10087 & 96,722 \\
\hline 1994 & 162014 & 29672 & 2799 & 2981 & 3240 & 460 & 10703 & 4225 & 9097 & 98,837 \\
\hline 1995 & 159780 & 17764 & 1686 & 3388 & 3677 & 711 & 11356 & 4477 & 11871 & 104,850 \\
\hline 1996 & 160540 & 18935 & 2634 & 395 & 4031 & 977 & 11367 & 4698 & 11084 & 106,419 \\
\hline 1997 & 151644 & 15695 & 2261 & 1210 & 3811 & 930 & 10768 & 4301 & 10061 & 102,607 \\
\hline 1998 & 158571 & 7590 & 15340 & 1299 & 3882 & 1087 & 11465 & 4330 & 11102 & 102,476 \\
\hline 1999 & 158529 & 7167 & 14646 & 1631 & 3902 & 1171 & 11600 & 4303 & 11727 & 102,382 \\
\hline 2000 & 153120 & 6207 & 12088 & 1807 & 3631 & 1055 & 11719 & 4291 & 10282 & 102,040 \\
\hline 2001 & 155337 & 7080 & 8693 & 2243 & 3798 & 1238 & 12309 & 4616 & 30225 & 85,135 \\
\hline All & 4447092 & 687759 & 93787 & 77768 & 90455 & 13508 & 449924 & 111578 & 375310 & 2547003 \\
\hline$\%$ & 100.0 & 15.5 & 2.1 & 1.7 & 2.0 & 0.3 & 10.1 & 2.5 & 8.4 & 57.3 \\
\hline
\end{tabular}


Table A2: A comparison of the raw and final samples from the NESPD with OECD statistics.

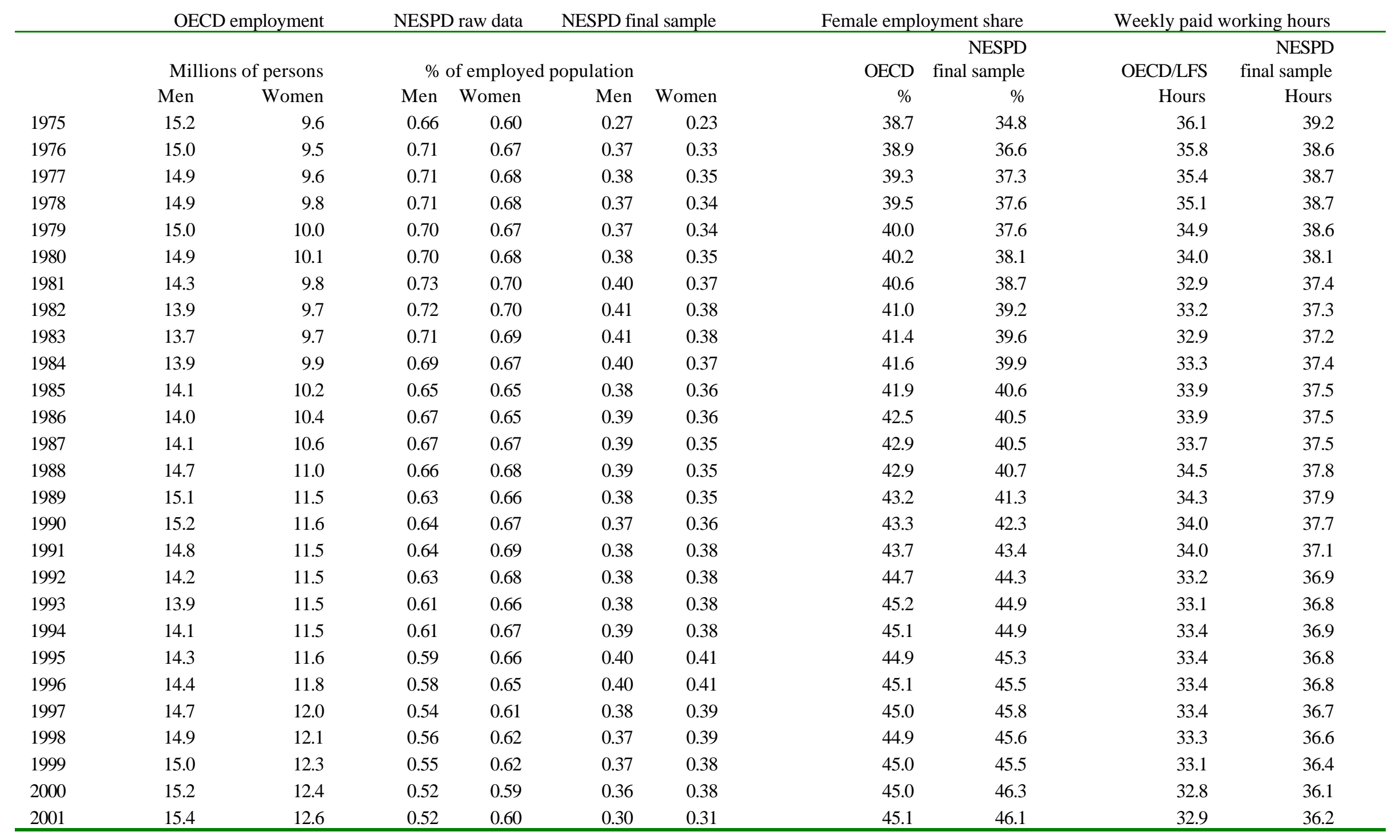


Table A3: Survivor rates in the sample, between periods $t$ and $t-s$.

\begin{tabular}{|c|c|c|c|c|c|c|c|c|}
\hline \multirow[t]{3}{*}{$\mathbf{s}$} & \multicolumn{4}{|c|}{ All birth-cohorts } & \multicolumn{4}{|c|}{ Birth-cohorts 1942-1954 } \\
\hline & \multicolumn{2}{|c|}{ Raw data } & \multirow{2}{*}{\multicolumn{2}{|c|}{$\begin{array}{r}\text { Selected sample } \\
\text { Men Women }\end{array}$}} & \multicolumn{2}{|c|}{ Raw data } & \multicolumn{2}{|c|}{ Selected sample } \\
\hline & Men & Women & & & Men & Women & Men & Women \\
\hline & $\%$ & $\%$ & $\%$ & $\%$ & $\%$ & $\%$ & $\%$ & $\%$ \\
\hline 0 & 100.0 & 100.0 & 100.0 & 100.0 & 100.0 & 100.0 & 100.0 & 100.0 \\
\hline 1 & 76.5 & 74.1 & 79.5 & 77.6 & 80.1 & 77.4 & 81.1 & 79.3 \\
\hline 2 & 61.6 & 58.1 & 58.9 & 55.3 & 66.9 & 63.0 & 62.2 & 58.6 \\
\hline 3 & 50.4 & 46.3 & 44.7 & 40.4 & 56.7 & 51.9 & 48.8 & 44.5 \\
\hline 4 & 41.7 & 37.3 & 34.5 & 29.9 & 48.4 & 43.2 & 38.9 & 34.2 \\
\hline 5 & 34.7 & 30.2 & 26.8 & 22.4 & 41.6 & 36.2 & 31.3 & 26.6 \\
\hline 6 & 28.9 & 24.6 & 21.0 & 16.8 & 35.8 & 30.4 & 25.4 & 20.7 \\
\hline 7 & 24.2 & 20.0 & 16.5 & 12.7 & 30.9 & 25.5 & 20.6 & 16.1 \\
\hline 8 & 20.2 & 16.3 & 13.0 & 9.6 & 26.6 & 21.4 & 16.9 & 12.6 \\
\hline 9 & 16.9 & 13.2 & 10.3 & 7.3 & 23.0 & 17.8 & 13.8 & 9.9 \\
\hline 10 & 14.1 & 10.7 & 8.1 & 5.5 & 19.7 & 14.8 & 11.3 & 7.7 \\
\hline 11 & 11.6 & 8.6 & 6.4 & 4.1 & 16.9 & 12.3 & 9.2 & 6.0 \\
\hline 12 & 9.6 & 6.8 & 5.0 & 3.1 & 14.3 & 10.1 & 7.5 & 4.6 \\
\hline 13 & 7.8 & 5.4 & 3.9 & 2.3 & 12.1 & 8.2 & 6.0 & 3.5 \\
\hline 14 & 6.4 & 4.3 & 3.0 & 1.7 & 10.2 & 6.7 & 4.8 & 2.7 \\
\hline 15 & 5.1 & 3.3 & 2.3 & 1.3 & 8.5 & 5.3 & 3.9 & 2.1 \\
\hline 16 & 4.1 & 2.6 & 1.7 & 0.9 & 7.0 & 4.2 & 3.0 & 1.5 \\
\hline 17 & 3.2 & 1.9 & 1.3 & 0.6 & 5.7 & 3.3 & 2.4 & 1.1 \\
\hline 18 & 2.5 & 1.5 & 1.0 & 0.4 & 4.6 & 2.6 & 1.8 & 0.8 \\
\hline 19 & 1.9 & 1.1 & 0.7 & 0.3 & 3.6 & 1.9 & 1.4 & 0.6 \\
\hline 20 & 1.4 & 0.8 & 0.5 & 0.2 & 2.8 & 1.4 & 1.0 & 0.4 \\
\hline 21 & 1.0 & 0.5 & 0.3 & 0.1 & 2.1 & 1.0 & 0.7 & 0.3 \\
\hline 22 & 0.7 & 0.4 & 0.2 & 0.1 & 1.5 & 0.7 & 0.5 & 0.2 \\
\hline 23 & 0.5 & 0.2 & 0.1 & 0.1 & 1.1 & 0.5 & 0.3 & 0.1 \\
\hline 24 & 0.3 & 0.1 & 0.1 & 0.0 & 0.7 & 0.3 & 0.2 & 0.1 \\
\hline 25 & 0.2 & 0.1 & 0.0 & 0.0 & 0.4 & 0.2 & 0.1 & 0.0 \\
\hline 26 & 0.1 & 0.0 & 0.0 & 0.0 & 0.2 & 0.1 & 0.1 & 0.0 \\
\hline
\end{tabular}


Appendix B: The incidence and hours of paid overtime, and the distribution of employment by occupation and industry.

\section{Table B1: By occupation.}

\begin{tabular}{|c|c|c|c|c|c|c|c|c|}
\hline \multirow[b]{2}{*}{ Year } & \multirow[t]{2}{*}{$\begin{array}{r}\text { Overtime } \\
\text { incidence }(\%)\end{array}$} & \multirow[t]{2}{*}{$\begin{array}{r}\text { Overtime hours per week } \\
\text { (if working overtime) }\end{array}$} & \multicolumn{6}{|c|}{ Share of employment (\%) } \\
\hline & & & 1975 & 1980 & 1985 & 1990 & 1995 & 2000 \\
\hline \multicolumn{9}{|l|}{ Panel A: Men } \\
\hline Managers and administrators & 11.8 & 6.0 & 7.1 & 8.8 & 9.0 & 10.8 & 16.0 & 18.3 \\
\hline Professional & 16.7 & 6.0 & 11.8 & 12.3 & 13.4 & 13.6 & 12.1 & 11.9 \\
\hline Associate professional/ technical & 23.6 & 5.9 & 7.4 & 8.4 & 9.3 & 9.9 & 9.3 & 9.5 \\
\hline Clerical and secretarial & 38.8 & 6.4 & 10.5 & 9.5 & 10.0 & 9.7 & 10.2 & 10.6 \\
\hline Craft and related occupations & 53.0 & 8.5 & 25.8 & 24.6 & 22.6 & 21.1 & 17.7 & 16.4 \\
\hline Personal and protective services & 51.8 & 7.1 & 4.3 & 4.7 & 5.5 & 5.6 & 6.1 & 6.4 \\
\hline Sales & 17.5 & 6.6 & 3.6 & 3.6 & 4.1 & 4.2 & 4.8 & 4.7 \\
\hline Plant and machine operatives & 59.1 & 9.7 & 20.8 & 20.2 & 18.2 & 17.7 & 16.4 & 15.1 \\
\hline Other & 56.5 & 9.7 & 8.7 & 8.0 & 7.9 & 7.5 & 7.3 & 7.2 \\
\hline All & 39.4 & 8.2 & 100.0 & 100.0 & 100.0 & 100.0 & 100.0 & 100.0 \\
\hline \multicolumn{9}{|l|}{ Panel B: Women } \\
\hline Managers and administrators & 11.7 & 3.4 & 1.6 & 2.1 & 2.4 & 3.7 & 7.9 & 10.0 \\
\hline Professional & 6.8 & 3.3 & 7.6 & 7.4 & 8.0 & 9.2 & 9.9 & 10.5 \\
\hline Associate professional/ technical & 11.4 & 3.5 & 7.9 & 9.6 & 12.2 & 12.6 & 11.5 & 11.5 \\
\hline Clerical and secretarial & 18.3 & 3.2 & 39.5 & 36.5 & 36.9 & 38.1 & 36.0 & 33.9 \\
\hline Craft and related occupations & 16.7 & 4.5 & 4.9 & 4.2 & 3.5 & 3.1 & 2.4 & 1.7 \\
\hline Personal and protective services & 15.6 & 4.5 & 7.6 & 8.9 & 9.1 & 8.3 & 10.0 & 11.8 \\
\hline Sales & 23.4 & 4.3 & 8.0 & 8.4 & 8.6 & 9.2 & 9.1 & 10.4 \\
\hline Plant and machine operatives & 23.6 & 4.9 & 9.7 & 8.5 & 6.4 & 5.9 & 4.8 & 3.8 \\
\hline Other & 15.2 & 4.5 & 13.1 & 14.5 & 12.9 & 10.0 & 8.4 & 6.5 \\
\hline All & 16.3 & 3.8 & 100.0 & 100.0 & 100.0 & 100.0 & 100.0 & 100.0 \\
\hline
\end{tabular}


Table B2: By industry.

\begin{tabular}{|c|c|c|c|c|c|c|c|c|}
\hline \multirow[b]{2}{*}{ Year } & \multirow[t]{2}{*}{$\begin{array}{r}\text { Overtime } \\
\text { incidence }(\%)\end{array}$} & \multirow[t]{2}{*}{$\begin{array}{r}\text { Overtime hours per week } \\
\text { (if working overtime) }\end{array}$} & \multicolumn{6}{|c|}{ Share of employment $(\%)$} \\
\hline & & & 1975 & 1980 & 1985 & 1990 & 1995 & 2000 \\
\hline \multicolumn{9}{|l|}{ Panel A: Men } \\
\hline Agriculture & 51.6 & 10.2 & 1.4 & 1.3 & 1.3 & 1.1 & 1.2 & 1.0 \\
\hline Energy and water supply & 42.4 & 7.6 & 5.4 & 5.2 & 5.3 & 4.6 & 3.0 & 2.0 \\
\hline Mineral extractions, metal and chemical products & 42.1 & 8.9 & 8.5 & 7.8 & 6.7 & 6.5 & 5.6 & 3.9 \\
\hline Metal goods and engineering products & 48.4 & 8.2 & 21.7 & 20.8 & 18.7 & 18.5 & 16.0 & 14.3 \\
\hline Other manufacturing industries & 43.7 & 9.0 & 12.2 & 11.5 & 10.8 & 10.8 & 11.1 & 9.8 \\
\hline Construction & 42.2 & 8.9 & 8.1 & 8.3 & 7.2 & 6.6 & 5.4 & 5.8 \\
\hline Distributive trades and catering & 31.8 & 7.3 & 8.2 & 10.0 & 10.9 & 11.5 & 13.5 & 15.2 \\
\hline Transport and communications & 56.0 & 10.0 & 12.5 & 11.3 & 10.8 & 10.6 & 10.1 & 9.9 \\
\hline Financial services & 24.6 & 5.6 & 4.9 & 6.0 & 7.7 & 10.6 & 12.8 & 15.6 \\
\hline Public administration & 33.0 & 6.2 & 9.8 & 9.2 & 9.7 & 9.2 & 8.9 & 8.3 \\
\hline Educational services & 12.0 & 6.4 & 2.7 & 3.5 & 3.8 & 3.0 & 4.6 & 6.4 \\
\hline Health services & 34.1 & 7.6 & 2.0 & 2.3 & 2.9 & 2.5 & 2.8 & 2.5 \\
\hline Business and other services & 29.1 & 7.5 & 2.4 & 2.9 & 4.2 & 4.6 & 5.1 & 5.2 \\
\hline All & 39.4 & 8.2 & 100.0 & 100.0 & 100.0 & 100.0 & 100.0 & 100.0 \\
\hline \multicolumn{9}{|l|}{ Panel B: Women } \\
\hline Agriculture & 18.2 & 4.8 & 0.3 & 0.3 & 0.3 & 0.2 & 0.3 & 0.4 \\
\hline Energy and water supply & 20.0 & 3.6 & 1.8 & 1.6 & 1.6 & 1.5 & 1.0 & 0.7 \\
\hline Mineral extractions, metal and chemical products & 15.6 & 4.1 & 3.5 & 3.0 & 2.3 & 2.2 & 1.9 & 1.5 \\
\hline Metal goods and engineering products & 20.3 & 4.1 & 9.5 & 8.1 & 6.3 & 5.7 & 4.6 & 3.6 \\
\hline Other manufacturing industries & 16.7 & 4.4 & 12.7 & 10.6 & 8.7 & 8.2 & 7.1 & 5.2 \\
\hline Construction & 8.7 & 3.9 & 1.1 & 1.1 & 1.1 & 1.1 & 0.9 & 1.0 \\
\hline Distributive trades and catering & 20.2 & 4.2 & 15.6 & 17.3 & 16.9 & 17.4 & 17.4 & 18.4 \\
\hline Transport and communications & 23.5 & 4.3 & 4.6 & 3.8 & 3.6 & 3.9 & 3.5 & 3.3 \\
\hline Financial services & 25.9 & 2.6 & 8.1 & 9.0 & 11.2 & 14.5 & 15.3 & 17.5 \\
\hline Public administration & 12.8 & 3.8 & 10.5 & 9.7 & 9.5 & 9.9 & 10.3 & 8.7 \\
\hline Educational services & 6.9 & 3.9 & 13.3 & 13.8 & 12.7 & 10.1 & 12.2 & 16.6 \\
\hline Health services & 11.4 & 3.7 & 12.6 & 14.5 & 17.0 & 15.3 & 14.5 & 13.3 \\
\hline Business and other services & 15.1 & 4.7 & 6.4 & 7.2 & 8.8 & 9.9 & 11.0 & 9.9 \\
\hline All & 16.3 & 3.8 & 100.0 & 100.0 & 100.0 & 100.0 & 100.0 & 100.0 \\
\hline
\end{tabular}

